\title{
Cloning and Analysis of DNA Sequence of Gene CylA of Enterococci Inducing Sheeps Encephalitis
}

\author{
Guijun Ma, Sujuan Han, Genqiang Yan \& Xia Zhou \\ College of Animal Sciences and Technology \\ ShiHeZi University/Laboratory of Xin jiang Endemic and Ethnic Diseases \\ Shihezi 832003, China \\ E-mail: shzmgj@163.com
}

\begin{abstract}
A DNA fragment was amplified from the chromosomal DNA of Eerococci Inducing Sheeps Encephalitis by PCR and then was cloned into pMD19-T Vector. The cloned fragment was sequenced. Comparing the DNA sequence of the amplified fragment with the published sequence of gene CylA showed that they were 99.3\% homologous.
\end{abstract}

Keywords: Eerococci inducing sheeps encephalitis, CylA cloning, DNA sequence

Enterococci are Gram-positive commensal bacteria inhabiting the alimentary canals of humans and animals. Recently, excessive employment of broad-spectrum antibiotics has created resistant strains. Enterococci infection has became an intractable problem in clinical treatment due to enterococci possessing intrinsic and acquired resistance (Wang Yan-hong \& Zhang Kou-xing 2005).This problem is now a hotspot within the study of enterococci.

In 2002 Nathan Shankar et al. (Nathan, Shankar \& Arto S. Baghdayan 2002) found a pathogenicity island in vancomycin-resistance Enterococcus faecalis. The virulence factors in E.faecalis, including a structurally novel toxin, the cytolysin, a surface protein, Esp, and an aggregation substance, which resided in this pathogenicity island. Expression of cytolysin (cyl), which is known to contribute to enterococcal virulence and have the ability to lyses erythrocyte, to kill leucocyte and to damage cordis cell (M.C.Booth et al. 1996, Y.Ike, H.Hashimoto \& D.B.Clewell 1987, Qiang Hua, Lin Jian-yin \& Jiang Ming-sen 2001). Some investigators reported it also poisoned neutrophils, aematoblast and spermatozoa cells (Yang Jin-song \& bao You-di.1997, Haas \& Wgilmore 1999). In our study the cylA gene fragment was amplified from the chromosomal DNA of enterococci inducing sheeps encephalitis by PCR and then was cloned into pMD19-T Vector. Then it was sequenced and found homologous with the published sequence of gene CylA. This study provides groundwork for studing the enterococcal molecular biology characteristics, expression of gene Cyl and biological activity of productions.

\section{Materials and methods}

\subsection{Bacterial strain and Vector}

The EA strain of enterococci Inducing Sheeps Encephalitis is conserved by our laboratory. Its serotype is lancefield group D (Qi Ya-yin,Yan Gen-qiang \& Wang Jing-mei 2005). Vector pMD19-T obtained from Takara.

\subsection{Chemicals.}

Restriction endonucleases (HindIII, EcoR I) and T4 DNA ligase were also from Takara. QIAquick Gel Extraction Kit, Taq DNA polymerase and dNTP were purchased from Shanghai Sangon Biological Engineering Technology \& Services Co.

\subsection{Preparation of Genomic DNA from EA strain.}

1.3.1 Inoculate $2 \mathrm{ml}$ of $\mathrm{LB}$ containing the ampicillin with a single colony of EA strain. Incubate the culture overnight at $37^{\circ} \mathrm{C}$ with vigorous shaking.

1.3.2 Pour $1.5 \mathrm{ml}$ of the culture into a microfuge tube. Centrifuge at maximum speed for 30 seconds at $4^{\circ} \mathrm{C}$ in a microfuge.

1.3.3 Resuspend the bacterial pellet in $50 \mu \mathrm{L}$ proteinase $\mathrm{K}(100 \mu \mathrm{g} / \mathrm{ml})$, then incubate the tube for 1 hour at $37^{\circ} \mathrm{C}$.

1.3.4 Add 200 $\mu \mathrm{L}$ lysis solution (Tris-HCl 40mmol/L, Natrium Acetate 20mmol/L, EDTA 1mmol/L, SDS 1\%), vigorous 
blow by tip.

1.3.5 Then add $60 \mu \mathrm{L} 5 \mathrm{~mol} / \mathrm{L} \mathrm{NaCl}$, Centrifuge the bacterial lysate at $12000 \mathrm{r} / \mathrm{m}$ for 10 minutes after full mix. This step eliminates residua of albumen compounds and cell-wall components.

1.3.6 Transfer the aqueous phase to a fresh centrifuge tube and add an equal volume of phenol equilibrated $0.1 \mathrm{~mol} / \mathrm{L}$ Tris- $\mathrm{Cl}(\mathrm{Ph} 8.0)$. Gently mix the two phases by turning the tube end-over-end for ten minutes.

1.3.7 Separate the two phases by centrifugation at $12000 \mathrm{r} / \mathrm{m}$ for 3 minutes at room temperature. Then a fresh centrifuge tube was used to collect the viscous aqueous phase.

1.3.8 Repeat the extraction twice and pool the aqueous phase.

1.3.9 Precipitate the DNA by adding an equal volume of isopropanol. Collect the precipitated DNA by centrifugation at $15000 \mathrm{rmp}$ for 15 minutes at $4^{\circ} \mathrm{C}$.

1.3.10 Carefully remove the isopropanol. Rinse the pellet of DNA with $1 \mathrm{ml}$ of $70 \%$ enthanol. Remove the $70 \%$ enthanol, and allow the pellets to dry in air for 15-20 minutes at room temperature.

1.3.11 Dissolve the mucleic acids in $50 \mu \mathrm{L}$ of TE $(\mathrm{Ph} 8.0)$ containing $20 \mu \mathrm{g} / \mathrm{ml}$ DNase-free RNase A. Store the DNA solution at $-20^{\circ} \mathrm{C}$.

\subsection{PCR primers and PCR amplification}

Both of the oligonucleotide primers chosen for amplification of cylA gene were selected from the published sequences with the assistance of the Primer Design software, P-I(5'GAC TCG GGG ATT GAT AGG C 3')and P-II(5'GCT GCT AAA GCT GCG CTT AC 3'), and the PCR product is 689bp. The oligonucleotides were synthesized by Shanghai Sangon. The reaction mixtures contained $1 \times \mathrm{PCR}$ buffer, $2 \mathrm{mM} \mathrm{MgCl}_{2}, 200 \mu \mathrm{M}$ each $\mathrm{dNTP}, 400 \mathrm{nM}$ each primer and $0.25 \mathrm{U}$ Taq DNA polymerase, $5 \mu \mathrm{L}$ DNA template. The final reaction volume was $50 \mu \mathrm{L}$. Samples were amplified on a DNA thermal cycler by heating for $5 \mathrm{~min}$ at $95^{\circ} \mathrm{C}$ for $60 \mathrm{~s}, 58^{\circ} \mathrm{C}$ for $60 \mathrm{~s}$ and $72^{\circ} \mathrm{C}$ for $60 \mathrm{~s}$, and a final step of $72^{\circ} \mathrm{C}$ for $10 \mathrm{~min}$. PCR products were analysed by gel electrophoresis in $1 \%(\mathrm{w} / \mathrm{v})$ agarose gel.

\subsection{Recovery and Purification of DNA fragments}

Recovery and Purification of DNA fractionated on agarose gels using QIAquick Gel Extraction Kit.

\subsection{Joined the target DNA}

The pMD19-T vector used in this experiment was purchased from Takara. The steps was followed the explaination. Place Confected DNA solution in sterile microfuge tubes in final volume $5 \mu \mathrm{L}$ mixtures, which contain: pMD19-T Simple Vector $1 \mu \mathrm{L}$, Control Insert $1 \mu \mathrm{L}$, Target DNA $3 \mu \mathrm{L}$. Then add an equal volume Ligation Mix. Incubate the reaction mixtures overnight at $16^{\circ} \mathrm{C}$.

\subsection{Preparation and Transformation of Competent E.coli}

E.coli used in this experiment was engineering bacterial Top 10. Preparation of competent E.coli using Calcium Chloride(Liu Jin-yuan,Chang Zhi-jie \& Zhao Guang-rong 2002). Add $10 \mu \mathrm{L}$ of DNA joined productions to polypropylene tube which contains $100 \mu \mathrm{L}$ of suspension of competent cells. Mix the contents of the tube by swirling gently. Store the tube on ice for 30 minutes. Transfer the tube to a rack placed in a preheated $42^{\circ} \mathrm{C}$ circulating water bath. Store the tubes in the rack for exactly 90 seconds. Rapidly transfer the tubes to an ice bath. Allow the cells to chill for $1-2$ minutes. Add $890 \mu \mathrm{L}$ of LB medium to the tube. Incubate the culture for $60 \mathrm{~min}$ at $37^{\circ} \mathrm{C}$ with vigorous shaking. Transfer the appropriate volume of transformed competent cells onto agar LB medium containing the amp, X-Gal, IPTG. Store the plate at room temperature until the liquid has been absorbed. Invert the plate and incubate at $37^{\circ} \mathrm{C}$ for 16 hours.

\subsection{Colony PCR and Plasmid DNA Enzyme Cutting}

The white colony was picked out, which was used as the PCR template for the identification of target DNA fragment. Plasmid DNA was isolated from small-scale white colony bacterial cultures by treatment with alkali and SDS and by digesting them with restriction enzymes whose sites flank the insert in the multiple cloning site. Enzyme cutting system contained plasmid DNA $10 \mu \mathrm{L}$,EcoR I $1 \mu \mathrm{L}$, Hind III $1 \mu \mathrm{L}, 10 \times$ Buffter $1 \mu \mathrm{L}$, add $\mathrm{ddH}_{2} \mathrm{O}$ to $20 \mu \mathrm{L}$.Incubated the mixtures for $3 \sim 6$ hours in a preheated $37^{\circ} \mathrm{C}$ circulating water bath.

\subsection{DNA Sequencing}

Selected positive colonies were punctured in the microfuge tubes containing LB solid medium. The sequencing of target DNA was undertaken by the Shanghai Sangon Sequence Dep.

\section{Results}

\subsection{PCR Amplification the Gene of CylA}

PCR products were analysed by gel electrophoresis in $1 \%(w / v)$ agarose gel as shown in Figure1. The amplification 
products were aggregated among the $600 \mathrm{bp}$ and $750 \mathrm{bp}$. That result was consistent with the target DNA fragment.

\subsection{Colony PCR}

Picked a number of white and blue colonies by transformation with the ligation reaction. Confirmed the presence of the amplified fragment by colony PCR. Consequently, white colony is positive clone and blue colony is negative clone, shown in Figure 2. Therefore, the white colony was positive cloning recombinant.

\subsection{Identification by Enzyme Cutting of Plasmid DNA}

Isolating the plasmid DNA and digesting them with restriction enzymes (EcoR I, Hind III), the cut-off fragment was around 750bp as shown in Figure 3. The enzymes cutting sites in the pMD19-T vector flank the insert about 30bp, respectively, and add the target DNA 689bp, which is consistent with above consequence.

\subsection{Sequencing}

The sequencing of the target DNA which was inserted into the pMD19-T vector was undertaken by using currency primer M13. Comparing the DNA sequence of the amplified fragment with the published sequence of gene CylA showed that they were $99.3 \%$ homologous with only six mutated nucleotides. The mutated nucleltides were matched with the corresponding site nucleotide in Genebank, respectively. The results are shown in the Figure 4.

\section{Discussion}

The E. faecalis cytolysin has been demonstrated to contribute to the virulence of enterococcal disease in a number of animal modelsas, as well as in humans. Studies about cytolysin in China are fewer than those of foreign countries and have been limitedt on the strains from nosocomial infections. In this study the cylA gene fragment was amplified from the chromosomal DNA of Eerococci Inducing Sheeps Encephalitis by PCR and cloned into pMD19-T Vector. Then sequencing and homologous comparison with the published sequence of gene CylA showed that they were $99.3 \%$ homologous with only six mutated nucleotides. The six mutated nucleltides were matched with the corresponding site nucleotide in Genebank, respectively. Taq DNA polymerase lacked 3'-5'exonuclease proofreading activities, sequence apparatus and software sometimes occurred fault or leak read,that both cases perhaps leaded to the mutation. This experiment supported the observation that the genes of the enterococcal cytolysin were consistent regardless whether the strains came from different regions and infections, human or animal. So we can further investigate the expression of gene Cyl and biological activity of productions.

Although scientists have been paying more attention to the antimicrobial resistance mechanisms of enterococcus and have one large numbers of studies, the study of the enterococcal pathogenesis as just begun. A number of studies over the years have addressed the issue of enterococcal virulence and the identification of enterococcal virulence factors (P.M.Tendolkar,A.S.Baghdayan \& N.Shankar 2003). Most prominent among these virulence determinants have been the surface adhesions Esp and aggregation substance(AS),collagen-binding protein Ace, secreted toxin cytolysin, secreted proteases gelatinase (gelE) and endocarditis antigen(efaA) et al.(BRADLEY,D.JETT,MARK \& M.HUYCKE 1994,P.M.Tendolkar,A.S.Baghdayan \& N.Shankar 2003). All these virulence determinants may contribute to the pathogenesis of enterococcal infection through a number of mechanisms; gelE, esp and cylA may play a crucial role in the pathogenic process (Roberta et al. 2004, H.A.Elsner et al. 2000, Ma Li-yan et al. 2005). The enterococcal cytolysin is a novel toxin that consists of two nonidentical, post-translationally modified subunits that interact to cause lysis of erythrocytes and other eukaryotic cells, and cytolysin is lethal for a wide range of Gram-positive bacteria (PHILLIP, S.COBURN, YNN \& E.HANCOCK 1999). Cytolysin is a crucial virulence factor for enterococcal infection and can aggravate the degree of enterococcal infection (Haas \& Wgilmore 1999). In some reports, genes of the cytolysin and the resistance may be presence some relation (L.De, Vuyst, M.R.F.Moreno \& H.Revets 2002, Colmar \& Homud.T 1987). The relations of those virulence factors and the mechanism of those pathogenic substances in enterococcal infection, remain to be explored. Therefore we identified the gene of the cylA by cloning and sequencing. In future research will involve cloning and expression of cytolysin protein and, according to that preparation, developing the antiserum for immunology detection, studing the enterococcal pathogenesis and developing the generic engineering bacterin.

\section{References}

BRADLEY, D. JETT, MARK \& M.HUYCKE. (1994). Virulence of Enterococci. CLINICAL MICROBIOLOGY REVIEWS, Oct, 462-478.

Colmar \& Homud. T. (1987). Enterococcus faecalis hemolysin-bacteriocin plasmids belong to the same incompatibility group. Appl Enviorn Microbiol, 53, 567.

Haas \& WGilmore. (1999). Molecular nature of a novel bacterial toxin: the cytolysin of Enterococcus ecalis. Med Microbiol Immunol, 187:183-190.

H.A.Elsner, I.Sobottka, D. Mack \& M.Claussen. (2000). Virulence Factors of Enterococcus faecalis and Enterococcus faecium Blood Culture Isolates. Eur J Clin Microbiol Infect Dis, 19 :39-42. 
L. De, Vuyst, M.R.F.Moreno \& H.Revets. (2002). Screening for enterocins and detection of hemolysin and vancomycin resistance in enterococci of different origins,Int. Food Microbiol, 2635, 1-20.

Liu, Jin-yuan, Chang, Zhi-jie \& Zhao, Guang-rong. (2002). Experimental Protocols for Molecular Biology, Tsinghua university press, $1-2$.

Ma, Li-yan, Xu, Shu-zhen \& Ma, Ji-ping. (2005). Advance in Study of Enterococcal Pathogenesis. Chinese Journal of Nosocomiology, 15 (3), 356-360.

Ma, Li-yan, Xu, Shu-zhen, Ma, Ji-ping. (2005). Detection of partial virulence determinants and phenotypes in Enterococci.Chinese Journal of Laboratory Medicine, 28(5), 529-532.

M. C. Booth, C. P. Bogie, H. G. Sahl, K. L. Hatter \& M. S. Gimore,. (1996). Structural analysis and proteolytic activation of Enterococcus faecalis cytolysin, a novel lantibiotic. Mol. Microbio,. 21, 1175-1184.

Nathan, Shankar \& Arto S. Baghdayan. (2002). Modulation of virulence within a pathogenicity island in vancomycin-resistant Enterococcus faecalis.Nature, 417:746-750.

PHILLIP, S. COBURN, YNN \& E. HANCOCK. (1999). A Novel Means of Self-Protection, Unrelated to Toxin Activation,Confers Immunity to the Bactericidal Effects of the Enterococcus faecalis Cytolysin. INFECTION AND IMMUNITY, July, 3339-3347.

P. M. Tendolkar, A. S. Baghdayan \& N. Shankar. (2003). Pathogenic enterococci: new developments in the 21st century. CMLS, Cell. Mol. Life Sci, 60, 2622-2636.

Qiang, Hua, Lin, Jian-yin \& Jiang, Ming-sen. (2001). The Relationship between Hemolysin and Virulence of Enterococci. Chinese Journal of Zoonoses, 17(6), 68-70.

Qi, Ya-yin, Yan, Gen-qiang \& Wang, Jing-mei. (2005). Isolation and Identification of Enterococcus Faecalis in Lambs with Meningitis.Journal of Shihezi University (Natural Science), 23(2), 200-202.

Roberta, Creti, Monica, Imperi \& Lucia, Bertuccini. (2004). Survey for virulence determinants among Enterococcus faecalis isolated from different Sources. Journal of Medical Microbiology, 53, 13-20.

Wang, Yan-hong \& Zhang, Kou-xing. (2005). Advance in Study of Enterococcal Infection.Section of Respiratory System Foreign Medical Sciences, 25(1), 38-40.

Yang, Jin-song \& Bao, You-di. (1997). Studies of Pathogenicity of Enterococci.Chinese Journal of Zoonoses, 13(6), 33-35.

Y. Ike, H. Hashimoto \& D. B. Clewell. (1987). High incidence of hemolysin production by Enterococcus (Streptococcus) faecalis strains associated with human parenteral infections. Clin Microbiol, 25, 1524-1528.

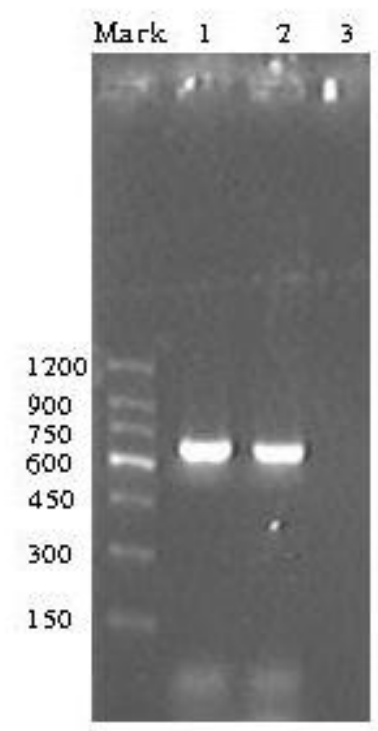

Figure 1. Electrophoretogram of EA CylA PCR products

Lane M: DNA Mark; Lane1,2:PCR product 689bp; Lane3:negative control 


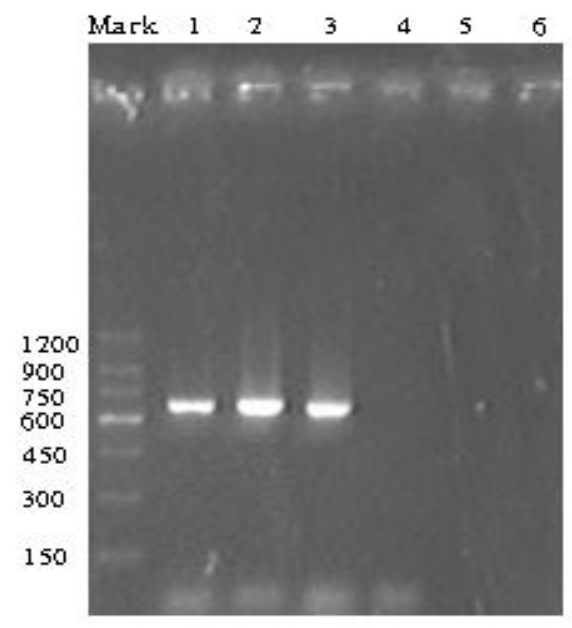

Figure 2. Identification of recombinant plasmid by PCR. Lane 1,2,3:PCR products of white colony; Lane4,5,6:PCR products of blue colony

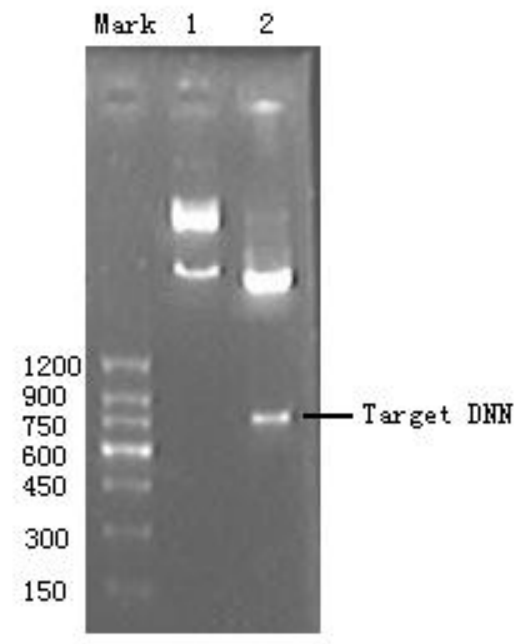

Figure 3. Restriction enzyme analysis of recombinant plasmid. Lane Mark: DNA Mark; Lane 1: The results of cloning plasmid extraction; Lane2: enzyme cutting results 


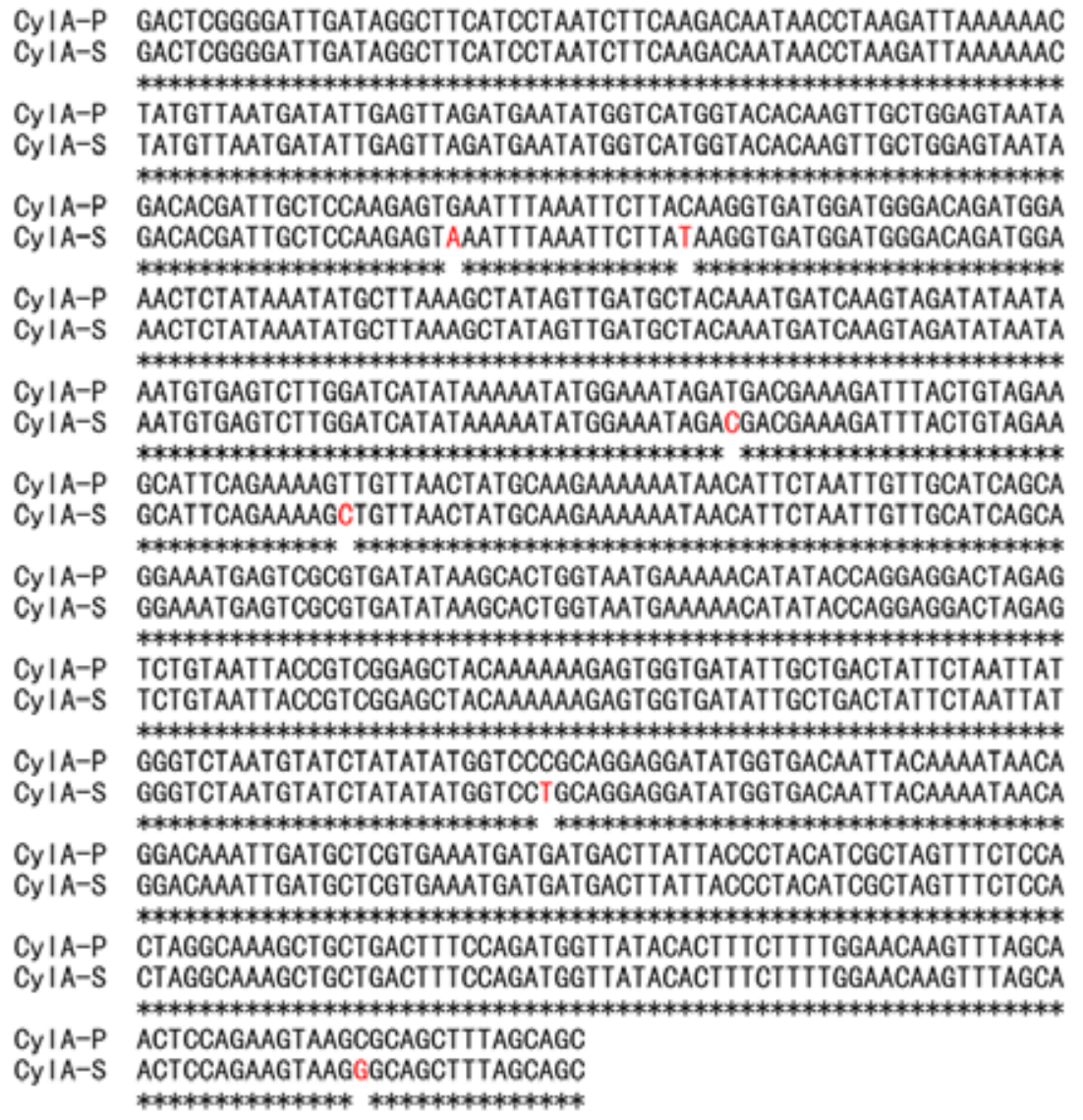

Figure 4. Results of Multiple sequence Alignment. CylA-P was published sequence; CylA-S was target DNA sequence; the underline part means Primer Sequence; the blackbodys means Mutation nucleotides. 